Kunkel, Nature 333, 863 (1988).

17. S. H. Orkin and S. C. Goff, J. Biol. Chem. 256 9782 (1981).

18. K. Takashita, B. Forget, A. Scarpa, E. J. Benz, Blood 64, 13 (1984).

19. J. M. Chirgwin, A. E. Przybyla, R. J. MacDonald, W. J. Rutter, Biochemistry 18, 5294 (1979).

20. H. Aviv and P. Leder, Proc. Natl. Acad. Sci. U.S.A. 69, 1408 (1972).

21. W. D. Benton and R. W. Davis, Science 196, 180 (1977).

22. G. S. Cross et al., EMBO J. 6, 3277 (1987).

23. F. Sanger, S. Nicklen, A. R. Coulson, Proc. Natl.
Acad. Sci. U.S.A. 74, 5463 (1977).

24. We thank $G$. Bulfield for the gift of inbred $m d x$ mice breeding pairs and K. Davies for the pCalA probe and $\mathbf{M}$. Goedert, D. Gussow, and J. Fleming for advice. American Type Culture Collection supplied partial cDNAs from the human dystrophin locus. P.S. held a European Molecular Biology Organization Fellowship. Y.G. holds a British Council Fellowship. A.R.C. held a Medical Research Council of Canada Fellowship. Supported by the Medical Research Council, United Kingdom.

14 February 1989; accepted 18 April 1989

\title{
Spatial Selectivity of Rat Hippocampal Neurons: Dependence on Preparedness for Movement
}

\section{Tom C. Foster, * Carl A. Castro, Bruce L. McNaughton}

The mammalian hippocampal formation appears to play a major role in the generation of internal representations of spatial relationships. In rats, this role is reflected in the spatially selective discharge of hippocampal pyramidal cells. The principal metric for coding spatial relationships might be the organism's own movements in space, that is, the spatial relationship between two locations is coded in terms of the movements executed in getting from one to the other. Thus, information from the motor programming systems (or "motor set") may contribute to coding of spatial location by hippocampal neurons. Spatially selective discharge of hippocampal neurons was abolished under conditions of restraint in which the animal had learned that locomotion was impossible. Therefore, hippocampal neuronal activity may reflect the association of movements with their spatial consequences.

$\mathrm{I}$ N RATS, THE HIPPOCAMPAL FORMAtion plays a major role in the encoding of spatial memory (1). Specifically, hippocampal pyramidal cells recorded in freely moving rats display both selectivity and memory for spatial location (2). In contrast, studies with restrained rabbits and primates emphasize hippocampal cellular involvement in associative learning (3), suggesting that neuron activity is related to learned stimulus-response contingencies (4). There is little sign of place-specific neuronal activation in such studies. However, the same cells that develop representations of conditioned responses also engage in spatial coding in extended environments (5), suggesting that the two types of activity may reflect processing of fundamentally similar kinds of information.

Two hippocampal cell types, complex spike (CS) and theta cells, can be identified electrophysiologically as pyramidal cells and interneurons, respectively (6). In the freely moving rat, both CS and theta cells discharge in phase with the rhythmic (theta) electroencephalogram (EEG) that accompanies orienting or translational movements,

Department of Psychology, University of Colorado, Boulder, CO 80303 .

*To whom correspondence should be addressed. that is, movements that carry the animal from one place to another (7). Furthermore, the responsiveness of CS cells to spatial location is modulated by the velocity and direction of movement (8), indicating a possible influence of "motor set" (9).

We investigated the possible role of motor set for location-specific discharge activity in freely moving and restrained rats. Four animals were trained to tolerate restraint, which was implemented by snugly wrapping the body and limbs in a towel fastened with clips. This procedure allowed the animal to
Fig. 1. Time histograms of two simultaneously recorded CS cells (cell 1 and cell 2) from one animal as it was manually transported from the place field of one cell (Loc. 1) into the place field of the other cell (Loc. 2) during the free (top panels) and restraint (lower panels) conditions; each place field thus served as a neutral location for the other place field (11). Spatially selective firing was abolished under the restraint condition. observe the environment by head movement and exploratory myostatial sniffing, while inhibiting attempts at displacement movements. Single units were isolated and recorded with "stereotrodes" (10) mounted in miniature manipulators. The manipulators were permanently implanted over the CAl region of the hippocampus in rats under pentobarbital anesthesia. Several weeks after surgery, well-differentiated units were identified as CS or theta cells according to established criteria. In unrestrained, or free, rats the discharge specificity of the cells was repeatedly tested by manually transporting the animal alternately to an identified place field for $5 \mathrm{~s}$, then to a neutral location for $5 \mathrm{~s}$ (11) (Fig. 1). The short interval between each transportation ensured that animals maintained an alert behavioral state. In some cases animals were left in one location long enough for us to examine unit activity during the large amplitude, irregular EEG activity (LIA) (voluntary prolonged immobility), which replaces the theta state after cessation of orienting or translational behaviors (12). Animals were then restrained and cells were again tested for place specificity and relation to EEG (Fig. 1). A recovery session was included to ensure the recording integrity. Behavior during the free, restraint, and recovery conditions was very similar in that animals engaged in head movements and myostatial sniffing. During free and recovery conditions animals also extended their limbs in anticipation of contact with the tabletop and made small shifts of posture. However, they were not actually locomoting during the 5-s sampling epochs.

Of 66 units recorded, 12 were classified as theta cells. The remaining $\mathbf{5 4}$ were identified as CS cells, of which 38 (70\%) exhibited place specificity in the experimental environment. Thirty-one of these cells could be monitored during the conditions of free, restraint, and recovery. There was an almost
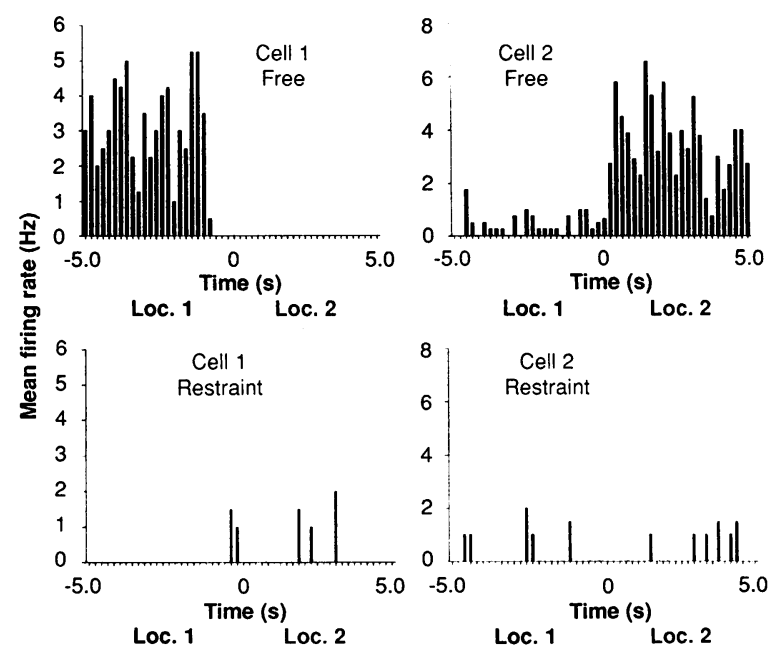


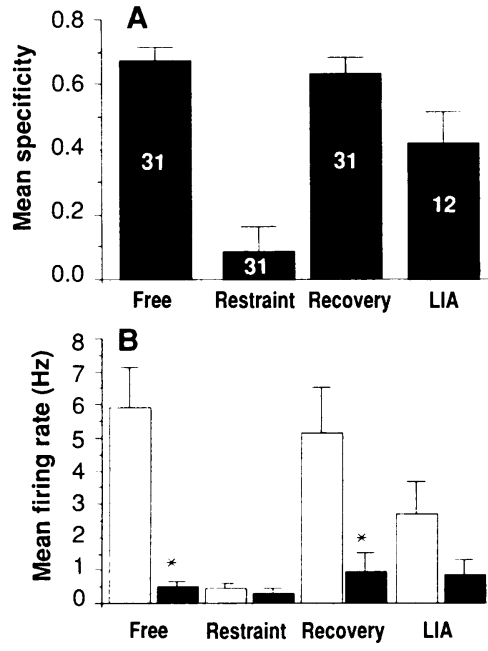

complete suppression of CS cell place specificity during restraint, compared to free and recovery conditions $[F(2,30)=55.35, P<$ 0.0001 ] (Fig. 2A). There was also an overall decrease in the discharge rate of CS [F $(2,30)=22.85, P<0.001]$ and theta cells during restraint $[F(2,11)=14.18, P<$ $0.005]$. The decrease in mean firing rate for CS cells was due almost entirely to decreased discharge in the previously determined place field $[F(2,30)=31.64, P<0.0001]$. No cell was observed to increase its firing rate during restraint. Although discharge activity in the place field was not significantly different from the neutral location in the restrained state (Fig. 2B), there was a small, but significant correlation between the specificity scores in the two states, indicating a very slight residual specificity. Place specificity scores for 12 CS units examined during LIA were slightly reduced, compared
Fig. 2. (A) Mean place specificity scores (11) for CS cells in the four behavioral conditions: free, restraint, recovery, and LIA. Numbers in bars represent units per treatment condition. There is a loss in specificity as a result of restraint and a slight decrease during LIA. (B) Mean discharge rate for $\mathbf{1 2}$ cells as animals were manually moved into the previously determined place field (open bars) or neutral location (solid bars) under the four behavioral conditions. The loss of specificity during restraint is entirely due to decreased discharge in the place field. Bars, mean + SEM; asterisks, significant difference $(P<0.05)$ between place field and neutral location.

to free and recovery conditions, confirming an earlier report (13) (Fig. 2A).

The hippocampal EEG under the different conditions exhibited a restraint-induced decrease in spectral power for type I (movement) theta (at about 7 to $10 \mathrm{~Hz}$ ) and increased power at lower frequencies (1 to 4 $\mathrm{Hz}$ ) (Fig. 3C). Furthermore, type II (sensory) theta (about $6 \mathrm{~Hz}$ ) (12) was not eliminated during the restraint condition, suggesting that the reduction in specificity was not due to inattention to environmental stimuli. Elimination of this sensory theta by atropine (25 to $50 \mathrm{mg} / \mathrm{kg}$ ) had no discernable effect on place specificity in either the free or restraint conditions. Thus, there was a dissociation between reduction of theta power and loss of place specificity (Fig. 3, A and $\mathrm{B}$ ).

Our results indicate that motor set makes a major contribution to spatially selective activity in CAl cells. This contribution may be simply a gating mechanism. Alternatively, information about actual movements or possible movements may play a more fundamental role in the representation of spatial
Fig. 3. (A) Mean place specificity scores (11) and $(B)$ mean EEG power ratio scores for 12 CS cells recorded from the CAl region of the hippocampus during the three behavioral conditions of free, restraint, and LIA. EEG scores were computed as the ratio of total spectral power in the 6- to $9-\mathrm{Hz}$ (theta) band divided by that for the 1- to 4-Hz (LIA) band. (C) Typical power spectra recorded in the CAl region of the hippocampus for one animal during the three be-
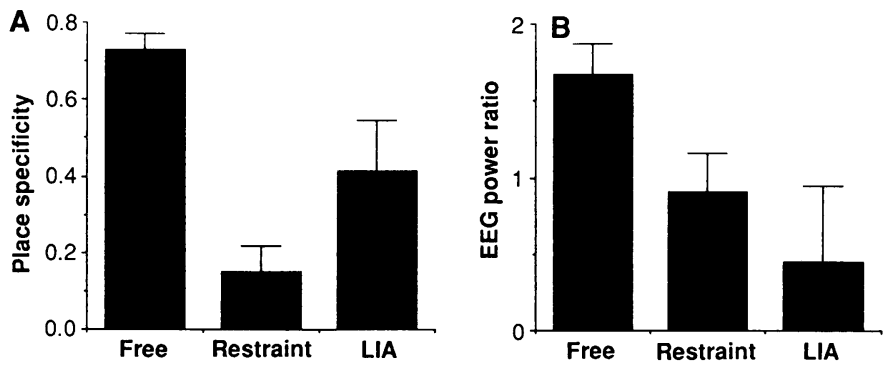

C

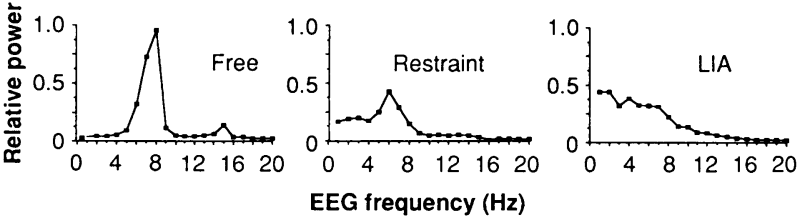

havioral conditions. Manually transporting the unrestrained (free) animals into and out of the place field was associated with high unit place specificity, intense EEG activity in the theta band, and lower power in the LIA band. Under restraint, the same manipulation was associated with an abolition of place specificity and only a moderate reduction in the EEG ratio (due to both a reduction of the higher frequency theta components and an increase in the LIA band). Under LIA the EEG power ratio was lowest, but there was only a partial reduction in place specificity. Thus, the loss of place specificity is not accounted for by the change in EEG state. Bars, mean + SEM. location. The persistence of head movement and exploratory sniffing in addition to type II (sensory) theta EEG activity recorded during restraint indicates that the animals were attending to environmental cues and also that such activity is not responsible for place-specific discharge. Although the loss of spatial firing was accompanied by a reduction of type I (movement-related) theta activity, the latter effect must be coincidental rather than causal, because inactivation of the medial septal projection to the hippocampus by local anesthesia completely abolishes both types of theta activity, with no effect on CAl place selectivity in freely moving animals (14). When free, animals could have moved, but they rarely did so apart from limb extension and some head and sniffing movements that were common to all conditions.

We thus favor the hypothesis that information on the preparedness for movement must be an intrinsic component of the information projected to the hippocampus by way of its cortical afferents, and this information on preparedness must do more than simply gate hippocampal output. The data are consistent with two related hypotheses concerning the role of hippocampal activity in spatial representation: a proposal that the spatial role of the hippocampus may be primarily that of learning about spatially directed movements (15) and a proposal that spatial representation involves the formation of conditional associations between representations of movements and representations of locations (16). In addition, other investigators (17) found that stimulusevoked unit activity in human hippocampus is decreased if subjects are instructed not to respond to the stimuli. Finally, the dependence of location-specific discharge on the animal's perceived ability to engage in movements through space may partly account for the relatively small number of spatially selective neurons recorded from hippocampus in primates and rabbits under conditions of restricted translational movement (4).

\section{REFERENCES AND NOTES}

1. J. O'Keefe and L. Nadel, The Hippocampus as a Cognitive Map (Clarendon Press, Oxford, 1978); J. O'Keefe and A. Speakman, Exp. Brain. Res. 68, 1 (1987).

2. J. O'Keefe and J. Dostrovsky, Brain Res. 34, 171 (1971); J. O'Keefe, Prog. Neurobiol. (Oxford) 13 419 (1979).

3. R. F. Thompson, T. W. Berger, S. D. Berry, F. K. Hoehler, Neural Mechanisms of Behavior (SpringerVerlag, New York, 1980); M. Mishkin, Philos. Trans. R. Soc. London Ser. B 298, 85 (1982).

4. R. F. Thompson, T. W. Berger, J. Madden, Annu Rev. Neurosci. 6, 447 (1983); T. Wantanabe and H. Niki, Brain Res. 325, 241 (1985); E. T. Rolls, Y. Miyashita, P. Cahusac, R. P. Kesner, Soc. Neurosci. Abstr. 13, 525 (1987) 
5. P. J. Best and R. F. Thompson, Soc. Neurosci. Abstr. $10,125(1984)$

6. S. E. Fox and J. B. Ranck, Jr., Exp. Neurol. 49, 299 (1975); T. C. Foster et al., Brain Res. 408, 86 (1987)

7. B. H. Bland, P. Andersen, T. Ganes, O. Sveen, Exp Brain Res. 38, 205 (1980); G. Buzsaki, L. S. Leung C. H. Vanderwolf, Brain Res. Rev. 6, 139 (1983).

8. B. L. McNaughton, C. A. Barnes, J. O'Keefe, Exp Brain Res. 52, 41 (1983).

9. Motor set is used in the general sense of preparedness for a particular movement [E. V. Evarts, Y. Shinoda, S. P. Wise, Neurophysiological Approaches to Higher Brain Functions (Wiley, New York, 1984)]

10. Stereotrodes [B. L. McNaughton, J. O'Keefe, C. A Barnes, J. Neurosci. Methods 8, 391 (1983)] consisted of two closely spaced $(20 \mu \mathrm{m})$ wires. Up to five cells at different distances from the two tips were discriminated at one time by their signal amplitude ratios on the two channels.

11. Unit data were collected as animals traversed a raised platform. On-line analysis identified the location of maximum discharge, that is, the "place field." Event flags inserted into the data stream marked corresponding spatial location for computation of spatial specificity scores. The EEG was filtered, digitized, and stored for off-line Fourier analysis. Mean firing rates for each location, for eight repetitions of each treatment condition, were used to calculate specific ity scores. The mean rate in the neutral location was subtracted from the mean rate in the place field, and this difference was divided by the sum of the two means. Treatment effects were assessed by one-way analysis of variance. Location of units in the CAl region was verified by histology.

12. C. H. Vanderwolf, Electroencephalogr. Clin. Neuro physiol. 26, 407 (1969); R. Kramis, C. H. Vanderwolf, B. H. Bland, Exp. Neurol. 49, 58 (1975).

13. R. U. Muller, J. L. Kubie, J. B. Ranck, Jr., J Neurosci. 7, 1935 (1987).

14. S. J. Y. Mizumori, B. L. McNaughton, C. A. Barnes, J. Neurosci., in press.

15. D. Gaffan, Philos. Trans. R. Soc. London Ser. B. 308 87 (1985); N. M. Rupniak and D. Gaffan, J. Neurosci. 7, 2331 (1987).

16. B. L. McNaughton, Neurosci. Lett. 29, S143 (1987) in Neural Connections and Mental Computations, L. Nadel, L. Cooper, P. Culicover, R. Harnish, Eds. (Academic Press, New York, 1989), pp. 285-350.

17. E. Halgren, T. L. Babb, P. H. Crandall, Electroencephalogr. Clin. Neurophysiol. 45, 585 (1987).

18. We thank C. A. Barnes for assistance and comments. Supported by PHS grants NS20331 and T32 HD07288.

26 January 1989; accepted 18 April 1989 subside during the next 15 to $30 \mathrm{~s}$, the cells continued to shrink, reaching a minimum volume at 10 to $30 \mathrm{~s}$ after the initial rise of $\left[\mathrm{Ca}^{2+}\right]_{\mathrm{i}}$. Maximum volume loss was $15 \% \pm 1 \%(n=25)$.

After the initial spike, the response of $\left[\mathrm{Ca}^{2+}\right]_{i}$ to the continued presence of carbachol varied among cells. Generally, $\left[\mathrm{Ca}^{2+}\right]_{\mathrm{i}}$ remained considerably higher than resting levels for as long as the agonist was present (Fig. 1, B and C). Removal of carbachol caused $\left[\mathrm{Ca}^{2+}\right]_{\mathrm{i}}$ to return rapidly to resting levels (Fig. 1, B and C). In some cells, $\left[\mathrm{Ca}^{2+}\right]_{\mathrm{i}}$ returned close to resting levels within $5 \mathrm{~min}$ in the continued presence of carbachol (Fig. 1D). Despite this variability among cells in the level and kinetics of the sustained phase of the $\left[\mathrm{Ca}^{2+}\right]_{i}$ response, cell volume was correlated with $\left[\mathrm{Ca}^{2+}\right]_{\mathrm{i}}$ in all cases. Thus, sustained elevated $\left[\mathrm{Ca}^{2+}\right]_{\mathrm{i}}$ was associated with sustained shrinkage (Fig. 1B); $\left[\mathrm{Ca}^{2+}\right]_{i}$ relaxation to intermediate levels was associated with the recovery of cell volume to intermediate levels (Fig. 1C), and transiently elevated $\left[\mathrm{Ca}^{2+}\right]_{i}$ was associated with shrinkage followed by volume recovery (Fig. 1D).

Secretagogues raise $\left[\mathrm{Ca}^{2+}\right]_{\mathrm{i}}$ by mobilizing $\mathrm{Ca}^{2+}$ from intracellular stores (10), possibly the endoplasmic reticulum (11) associated with the basolateral membrane (12), as well as by enhancing plasma membrane $\mathrm{Ca}^{2+}$ permeability (10). In the presence of agonist and extracellular $\mathrm{Ca}^{2+}\left(\mathrm{Ca}^{2+}{ }_{\mathrm{o}}\right), \mathrm{Ca}^{2+}$ entry resulted in a sustained elevation of $\left[\mathrm{Ca}^{2+}\right]_{\mathrm{i}}$ in most of the acinar cells examined (Fig. 1, $\mathrm{B}$ and $\mathrm{C})$. In the absence of $\mathrm{Ca}^{2+}$, stimulation was associated with a peak $\left[\mathrm{Ca}^{2+}\right]_{\mathrm{i}}$ $(712 \pm 115 \mathrm{nM})$, which was comparable $(P=0.4)$ to that observed for cells stimulated in $\mathrm{Ca}^{2+}$-containing medium. However $\left[\mathrm{Ca}^{2+}\right]_{\mathrm{i}}$ generally returned to resting levels within $3 \mathrm{~min}$ as intracellular stores became depleted (Fig. 2A). Associated with the $\left[\mathrm{Ca}^{2+}\right]_{\mathrm{i}}$ spike was a rapid cell shrinkage (volume loss, $15 \% \pm 1 \%$ ) indistinguishable from that observed in $\mathrm{Ca}^{2+}$-containing medium. In cells stimulated in the absence of $\mathrm{Ca}^{2+}$ o, however, the shrinkage was transient, and the cells recovered their volumes with a time course that was comparable with the recovery of $\left[\mathrm{Ca}^{2+}\right]_{i}$ (Fig. 2A). These data indicate that mobilization of $\left[\mathrm{Ca}^{2+}\right]_{\mathrm{i}}$

J. K. Foskett, Physiology Department, Armed Forces Radiobiology Research Institute, Bethesda, MD 20814. J. E. Melvin, Clinical Investigations and Patient Care Branch, National Institute of Dental Research, National Institutes of Health, Bethesda, MD 20862.

* Present address and to whom correspondence and reprint requests should be addressed at Division of Cel Biology, Research Institute, The Hospital for Sick Children, 555 University Avenue, Toronto, Ontario M5G IX8, Canada.

†Present address: Department of Dental Research, University of Rochester, Box 611, 605 Elmwood Ave. Rochester, NY 14642 influencing the driving forces for secretion, and rapid alterations of cell size may modu- $\mathrm{n} M(n=31)$ within 3 s. Shrinkage was detected close to the time that $\left[\mathrm{Ca}^{2+}\right]$ reached peaked levels (Fig. 1A). Even though the $\left[\mathrm{Ca}^{2+}\right]_{\mathrm{i}}$ increase usually began to 